
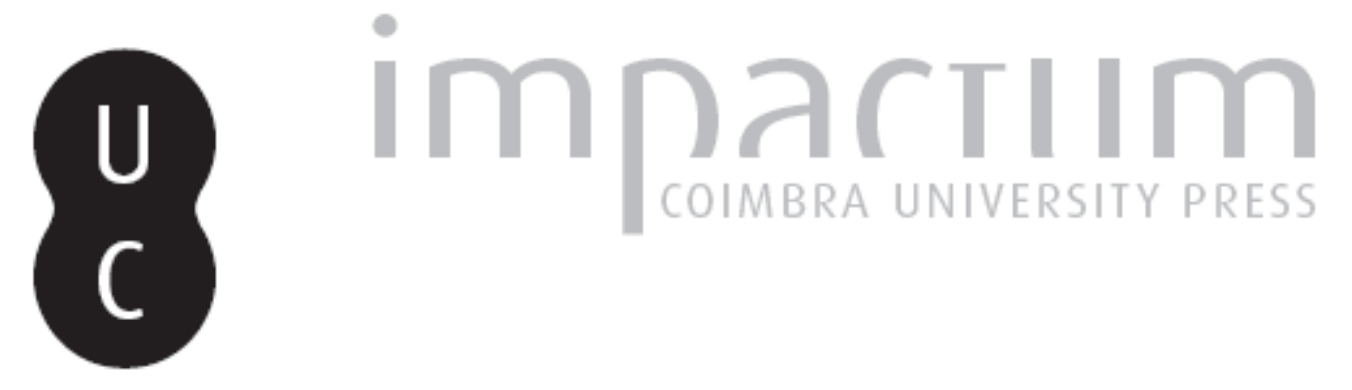

\title{
Biocaching: lazer, turismo e património
}

Autor(es): $\quad$ Alves, Luiz; Carvalho, Paulo

Publicado por: Imprensa da Universidade de Coimbra

URL persistente:

URI:http://hdl.handle.net/10316.2/38321

DOI:

DOI:http://dx.doi.org/10.14195/0871-1623_34_11

Accessed : $\quad$ 26-Apr-2023 13:50:44

A navegação consulta e descarregamento dos títulos inseridos nas Bibliotecas Digitais UC Digitalis, UC Pombalina e UC Impactum, pressupõem a aceitação plena e sem reservas dos Termos e Condições de Uso destas Bibliotecas Digitais, disponíveis em https://digitalis.uc.pt/pt-pt/termos.

Conforme exposto nos referidos Termos e Condições de Uso, o descarregamento de títulos de acesso restrito requer uma licença válida de autorização devendo o utilizador aceder ao(s) documento(s) a partir de um endereço de IP da instituição detentora da supramencionada licença.

Ao utilizador é apenas permitido o descarregamento para uso pessoal, pelo que o emprego do(s) título(s) descarregado(s) para outro fim, designadamente comercial, carece de autorização do respetivo autor ou editor da obra.

Na medida em que todas as obras da UC Digitalis se encontram protegidas pelo Código do Direito de Autor e Direitos Conexos e demais legislação aplicável, toda a cópia, parcial ou total, deste documento, nos casos em que é legalmente admitida, deverá conter ou fazer-se acompanhar por este aviso. 


\title{
Biocaching: lazer, turismo e património' Biocaching: leisure, tourism and heritage
}

\author{
Luiz Alves \\ Doutorando em Geografia. Faculdade de Letras. Universidade de Coimbra \\ luizalves90@hotmail.com
}

\section{Paulo Carvalho}

Departamento de Geografia e Turismo. Faculdade de Letras. Universidade de Coimbra e Centro de Estudos de Geografia e Ordenamento do Território paulo.carvalho@fl.uc.pt

\section{Resumo:}

Uma das dimensões mais recentes do geocaching decorre da sua utilização como ferramenta de aprendizagem no domínio da biologia (com ligação ao conjunto das ciências da vida e da terra), assumindo a designação de biocaching. Neste particular a vinculação estreita à vertente botânica (fitogeográfica) faz desta atividade uma ferramenta a considerar designadamente nas estratégias de salvaguarda e valorização do património natural biótico, além do seu potencial como atividade de lazer ao ar livre.

À guisa de abordagem preliminar, pretende-se enfatizar o enquadramento teórico-conceptual subjacente a esta temática, com uma revisão de literatura científica adequada, bem como explicitar a sua vertente empírica (que inclui a apresentação das linhas gerais de um exemplo concreto de implementação em estreita articulação às árvores notáveis/de interesse público e domínios patrimoniais complementares).

Palavras-chave: Lazer. Turismo. Património. Biocaching.

\section{Abstract:}

One of the latest dimensions of geocaching stems from its use as a learning tool in the field of biology (with connection to all life and earth sciences), assuming the name of biocaching. This particular narrow strand binding botany (phytogeographical) makes this activity a tool to consider in particular the strategies of protection and valorization of the natural biotic heritage, apart from its potential as a leisure activity outdoors.

By way of preliminary approach, it is intended to emphasize the theoretical-conceptual framework underlying this theme, with a review of the scientific literature, as well as clarifying the empirical aspect (which includes the presentation of the outlines of a concrete example of implementation in close coordination to notable trees/of public interest and additional equity domains).

Keywords: Leisure. Tourism. Heritage. Biocaching.

\section{Lazer, turismo e património}

Na sociedade contemporânea, o lazer materializa um número crescente e uma diversidade de práticas, com novas escolhas geográficas associadas. $\mathrm{Na}$ génese deste processo (de crescimento e de alargamento) encontramos uma evidente amplitude de motivações, que inclui preocupações de saúde e bem-estar, enriquecimento cultural, imagem e estética individual, solidariedade, responsabilidade, ética, entre outras.

As atividades que decorrem ao ar livre designadamente as que conciliam exercício físico, fruição, ensino/aprendizagem e experimentação, são, porventura, aquelas que mais influenciam a ocupação e a organização espacial e, portanto, as de maior relevância no que diz respeito às dinâmicas territoriais.

Passeios pedestres, cicloturismo, downhill, observação de fauna e flora, geocaching, são alguns exemplos de práticas de lazer ativo ao ar livre, que em certos casos pode assumir uma dimensão desportiva e/ou turística, em contextos geográficos desenhados na amplitude do rural ao urbano, embora os ambientes rurais e as montanhas correspondam de forma mais recorrente aos quadros matriciais de génese e consolidação das referidas práticas (Carvalho, 2015).

O turismo é uma das atividades de maior expressão no âmbito do lazer, assumindo, desde meados do século passado, uma importância cada vez maior, quer no contexto da economia, quer na esfera social, académica ou política. 
Jamal e Robinson (2009) advogam que o turismo é um fenómeno global, com causas e consequências para as populações que ultrapassam as fileiras daqueles que operam e praticam esta atividade; assinalam ainda que estudar turismo permite a exploração do significado das experiências de ser turista e fazer turismo, para além de possibilitar o envolvimento com algumas das questões-chave da globalização e da pós-modernidade.

Nas últimas décadas registam-se importantes alterações na atividade turística, tendo em vista ajustar a oferta a uma procura cada vez mais segmentada, informada e exigente, de tal maneira que, com diferentes expressões (alternativo, novo, complementar, entre outras) para designar as principais mudanças epistemológicas, o turismo pós-moderno revela novas tipologias, é mais personalizado, é desenhado à medida e orientado para proporcionar aos turistas a vivência de experiências únicas, de momentos de grande valor simbólico e em que a criatividade é uma preocupação recente. Ao mesmo tempo, com a integração de preocupações de sustentabilidade e princípios éticos, os recursos naturais e culturais emergem na vanguarda do planeamento e desenvolvimento desta atividade.

Importa explicar que o turismo corresponde a um sistema complexo, diversificado e dinâmico, que envolve recursos, equipamentos e infraestruturas, agentes e operadores, instrumentos normativos e orientadores, entre outros, com uma evidente dimensão territorial, que não sendo apenas física, é também relacional - o que traduz o carácter dinâmico do território e as formas de organização que tendencialmente valorizam as redes.

Como refere Menezes (2009: 21), citando Croce e Perri (2008), "o território é edificado por um conjunto de recursos que devem ser preservados e desenvolvidos ao longo do tempo, em sintonia com as preocupações ambientais, sociais e de sustentabilidade económica".

Os recursos devem ser salvaguardados e valorizados, uma vez que são fundamentais para gerar produtos turísticos e também para o próprio sistema turístico. Este último, nas suas diversas configurações, gera ofertas com capacidade de criar valor acrescentado para segmentos específicos de mercado como, por exemplo, o turismo literário, o turismo gastronómico, o enoturismo, o turismo industrial, o turismo fluvial, o turismo de passeio pedestre ou o turismo equestre.

Com efeito, os recursos são a base dos diferentes produtos tendo em vista oferecer experiências únicas e responder aos interesses (cada vez mais diversificados) dos turistas, e materializam atributos diferenciadores dos territórios que podem assumir um papel destacado no contexto do seu posicionamento competitivo, para além de contribuir para associar essas características únicas à imagem/ marca dos lugares - o que pode aumentar o valor do produto ou do serviço oferecido.

Nesta perspetiva, destaca-se o património, nas suas diferentes vertentes/expressões (natural, cultural, paisagístico; material, imaterial), e a sua utilização em diversas iniciativas de desenvolvimento, que inclui os parques (temáticos, biológicos, patrimoniais, arqueológicos, geoparques), os eventos culturais (feiras, festivais, mostras, recriações históricas), e os lazeres turísticos (com novos produtos destinados a captar segmentos específicos da procura), entre outras, na amplitude de contextos (rurais, urbanos, periurbanos), ambientes (campo, cidade, montanha, águas interiores e litorais) e escalas geográficas (lugares, rotas, redes) de geometria variável, que traduzem também novas formas de relacionamento de atores e de integração de territórios - cooperação, parceria, inclusão, inovação, criatividade, participação são algumas das palavras-chave que marcam os projetos e as ações mais relevantes.

0 reconhecimento do valor excepcional dos recursos ecoculturais conduz aos estatutos de proteção patrimonial e aos processos classificação de lugares, enquanto mecanismos de salvaguarda de bens/sítios únicos (que podem assumir uma dimensão local, regional, nacional, internacional ou universal, bem como materializar diferentes formas de reconhecimento em simultâneo) e plataformas indutoras da sua valorização através de iniciativas desenhadas na amplitude dos centros de interpretação da paisagem, aos espaços museológicos, sem esquecer as propostas concretas de descoberta e fruição dos lugares e dos seus patrimónios in loco, no espectro das suas dimensões visuais, sonoras e olfativas, em que o pedestrianismo e o geocaching são dois exemplos paradigmáticos (traduzindo, de igual modo, o reconhecimento dos benefícios físicos e psicológicos destas atividades ao ar (ivre).

\section{Do geocaching ao biocaching}

O geocaching assume-se com uma caça ao tesouro dos tempos modernos, jogado um pouco por todo o mundo, por pessoas com espírito aventureiro (CURATO, 2013) e com vontade de conhecer novos locais, e equipados com recetores de GPS (Global Positional System). Em termos gerais, a ideia base do jogo é encontrar recipientes escondidos, denominados geocaches, referenciados através de coordenadas geográficas e depois partilhar a experiência da aventura online (CURATO, 2013; FERNANDES, 2013), sendo que todas as geocaches devidamente registadas se encontram publicadas no site geocaching.com.

"O geocaching tem registado um crescimento exponencial do número de praticantes/aderentes em todo o Mundo e, de forma particular, em Portugal, perspetivando-se que continue a crescer nos próximos anos o que, enquanto atividade de lazer, consubs tancia uma oportunidade muito interessante para promover dinâmicas positivas de desenvolvimento nos territórios onde ocorre designadamente os rurais e de montanha" (ALVES e CARVALHO, 2015:32).

Num quadro de 22.093 geocaches ativas em Portugal e de 40.586 geocachers registados em território nacional (em 11 de julho de 2013), que contava, no mesmo período temporal, com 2.346.823 de geocaches ativas e um total de geocachers que ul- 
trapassa os 6 milhões em todo o mundo, torna-se evidente a importância deste lazer no quadro de desenvolvimento dos territórios e, em especial, nos de matriz rural e de montanha.

"O geocaching é uma excelente forma de explorar locais novos (uma vez que algumas geocaches estão escondidas em locais de interesse histórico ou de grande beleza natural, e que o geocaching ajuda/ permite descobrir); permite juntar amigos e família em atividades ao ar livre, em contacto com a natureza; pode ser uma atividade desafiadora, visto que algumas das geocaches estão muito bem escondidas; é um ótimo complemento a outras atividades de lazer, como caminhadas, passeios de bicicleta, de jipe ou de barco" (ALVES e CARVALHO, 2015: 34).

Uma outra corrente/vertente do geocaching tem-se interessado pela divulgação e valorização do património natural, com especial interesse nos domínios da fauna e flora. 0 designado biocaching tem na sua génese as práticas inerentes ao geocaching, embora com algumas variações. Em termos gerais podemos ter duas perspetivas distintas na forma de aplicação/implementação do biocaching: a criação de uma geocache num local com elevado valor biológico (seguindo os trâmites correntes de aplicação de uma geocache, com registo online no site geocaching.com, suporte físico no local com material para registar a visita); a criação de materiais variados para públicos-alvo específicos, praticantes de geocaching ou não, inseridos em atividades de lazer, de enriquecimento curricular, ou de ocupação de tempos livres(folhetos, georreferenciação de flora em guias de divulgação de territórios, folhetos de percursos pedestres com identificação de locais com potencial no domínio do biocaching, conteúdos didácticos com georreferenciação de elemtentos fitogeográficos como elemento de apoio à aprendizagem nos domínios da biologia para alunos), organizadas por gestores de territórios com património natural classificado, empresas de animação turística, postos e gabinetes de turismo, poder local, organismos regionais de turismo, professores, investigadores, entre outros.

É dificil estabelecer quando e onde se iniciou esta abordagem focada no biocaching. Porém, várias informações indicam que a utilização desta terminologia deriva da aplicação da metodologia geocaching para facilitar e melhorar processos de aprendizagem nos domínios da biologia, em contexto de ensino criativo. Na verdade, a própria designação “biocaching" remete para uma curiosidade interessante, referente à sua aplicação. O termo "bio", derivado da palavra "biologia", remete a ciência que estuda os seres vivos e as suas leis orgânicas. Porém, de facto, no caso concreto do biocaching, por norma, a sua aplicação é feita, predominantemente, aos elementos da flora (plantas), pela evidência de que é muito mais fácil georreferenciar um elemento estático, e tê-lo disponível sem alterações da sua posição, ou contrário do que sucede com a fauna, eminentemente sem posição fixa e/ou definida. Neste caso o biocaching remete, particularmente para "fitocaching", na sua definição terminológica.

\section{Exemplos e potencialidades de aplicação do biocaching}

São vários os exemplos que podemos encontrar no que se refere a esta aplicação das tecnologias geográficas aliadas ao ensino da biologia.

Num estudo desenvolvido na Holanda (2010), Sijmen Tenwolde e Joris Veenhoven, analisaram o impacto e a importância das novas tecnologias na educação, sendo o biocaching um dos projectos educacionais considerados. Nesse caso, o biocaching foi apontado como uma forma motivante para os alunos recolherem informações e aprendizagem, devido à forma prática, à diversão resultante da interação em grupo no decorrer da atividade. Foi, igualmente, considerado que esta aplicação é adequada para todos os níveis de ensino, devido à promoção da cooperação, trabalho de equipa, incentivo à prática de atividades de ar livre e motivação no domínio da aprendizagem de conteúdos, com resultados práticos na aquisição dos mesmos.

Num outro caso, em Wisconsin, Estados Unidos da América, o biocaching é, igualmente, utilizado como ferramenta de ensino no domínio da biologia, em contraponto com as viagens de campo tradicionais. Neste caso, os alunos fazem um percurso com cerca de três quilómetros, ao longo de Green Lake County's White River Wildlife Area. Para incorporar a tecnologia GPS no currículo de biologia, Thomas Eddy, desenvolveu "uma forma híbrida de geocaching chamado BioCache. O BioCache é composto por equipas de estudantes que navegam uma rota desconhecida utilizando GPS, participando numa procura, e localizar geocaches personalizadas". Em tudo este processo é igual ao geocaching. Porém, para adicionar o conteúdo de aprendizagem da biologia, em cada container são adicionadas folhas, galhos, e amostras de plantas para os alunos identificarem. Associado ao processo de aprendizagem nos domínios da biologia (ou da fitogeografia), cada membro da equipa (de alunos) tem uma tarefa distinta, um fator extra muito importante para o desenvolvimento os domínios cognitivos, de interação, trabalho de equipa e cooperação. A avaliação dos alunos durante o designado BioCache é baseada na contribuição de cada um no seio da equipa, na navegação bem-sucedida através da rota estabelecida, na localização das geocaches e participação na atividade. Thomas Eddy, professor que implementou esta forma diferenciada de ensino, considera que o BioCache não é apenas um portal para aprender nos domínios da natureza e da ecologia integrando, também, desenvolvimento de conhecimentos na tecnologia GPS, geografia e história natural. Remata, afirmando que o "BioCache facilita o trabalho em equipa, oferece um desafio de recreação ao ar livre, aguça as habilidades de observação, e reforça a aprendizagem feita na sala de aula”.

Um outro exemplo da aplicação do biocaching nos moldes anteriormente descritos, pode ser encontrado em Coonarr, Queensland (Austrália). Neste caso concreto, através dos dados disponíveis no Atlas of Living Australia (http://www.ala.org.au/data-sets/), 
que contém informações sobre todas as espécies conhecidas na Austrália agregados a partir de informações disponibilizadas por várias entidades: museus, herbários, grupos comunitários, departamentos governamentais, indivíduos e universidades, os professores de biologia utilizam a ferramenta biocaching para promover, junto dos seus alunos, a aprendizagem da biologia com esta técnica de ensino diferenciada, com várias biocaches implementadas numa área superior a 10.000 hectares.

Por outro lado, encontramos, de igual modo, o aproveitamento do biocaching como forma de diferenciação de territórios nos domínios do lazer e do turismo, valorizando o seu património natural a partir desta ferramenta. A título de exemplo, podemos referir o guia botânico desenvolvido, em 2012, em Vaňovská, no vale do rio Labe (República Checa), que identificou mais de 850 plantas, das quais 150 estão incluídas na Lista Vermelha de Plantas na República Checa. A identificação de parte destas plantas, está disponibilizada no mencionado guia em formato biocaching, com identificação de cada planta, breve descrição da mesma, integração nos habitats, além das coordenadas GPS e do grau de dificuldade de acesso ao local específico (Figura 1).

Em Portugal encontramos uma aplicação interessante da utilização do biocaching no desenvolvimento de atividades de lazer com um cunho de aprendizagem de conteúdos científicos de elevedo interesse e importância.

No contexto das ofertas disponibilizadas pelo Programa Ciência Viva no Verão (com a designação: "Nas férias a ciência sai à rua"), a Agência Nacional para a Cultura Científica e Tecnológica em parceria com a Fundação para a Ciência e a Tecnologia prepararam mais de 1600 acções por todo o país, de 15 de julho a 15 de setembro, em cooperação com instituições científicas, centros de ciência e empresas. Neste programa as temáticas desenvolvidas centram-se em torno de seis domínios fundamentais: astronomia, geologia, biologia, engenharia, faróis e castelos.

No caso concreto do biocaching foram organizadas duas sessões, ambas na Serra da Lousã, enquadradas nas atividades de "Biologia no Verão", do referido programa. Com a denominação "Biocaching Serra da Lousã I" (Figura 2) e "Biocaching Serra da Lousã II", estas sessões decorreram a 19 de julho e 6 de setembro, respetivamente, com ponto de encontro em locais do concelho de Castanheira de Pêra, sendo a entidade promotora o Centro Ciência Viva de Coimbra - Exploratório Infante $\mathrm{D}$. Henrique, e o responsável pelas ações José Augusto Pais (engenheiro florestal).

Estas iniciativas apresentaram como mote o desenvolvimento de um jogo de descobertas por dois dos setores mais ricos e fascinantes da Serra da Lousã (que faz parte da Cordilheira Central, localizada no coração da Região Centro de Portugal): o vale da ribeira de Pêra até às imediações da aldeia do Coentral, no concelho de Castanheira de Pêra e o maciço central da Serra da Lousã, nas envolvências da nascente da ribeira de Alge, nos limites administrativos dos concelhos de Castanheira de Pêra, Figueiró dos Vinhos e Lousã.

\section{Considerações finais}

$\mathrm{Na}$ atualidade, o lazer é sinónimo de uma crescente amplitude e diversidade de práticas, designadamente as atividades que decorrem ao ar livre e, destas, em particular aquelas que interligam exercício físico, fruição, ensino/aprendizagem e experimentação como é o exemplo do geocaching.

O geocaching consiste na procura de recipientes escondidos, denominados geocaches, referenciadas através de coordenadas GPS e na partilha da experiência/aventura da sua descoberta online (sendo que todas as geocaches devidamente registadas se encontram publicadas no site geocaching.com). Apesar de constituir uma atividade com pouco mais de uma dezena de anos, o geocaching tem registado um crescimento exponencial do número de praticantes/ aderentes em todo o Mundo e, de forma particular, em Portugal, perspetivando-se que continue a crescer nos próximos anos o que, enquanto atividade de lazer, consubstancia uma oportunidade de enorme relevância para descobrir, promover e desenvolver os territórios onde ocorre, em estreita ligação aos recursos ecológicos e culturais (Alves e Carvalho, 2015).
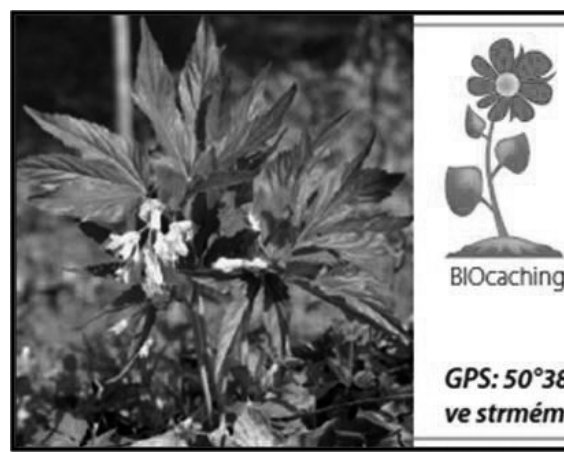

Za kyčelnici do "horské strže"

Ve vlhké úžlabině na strmém svahu nad Vaňovem roste populace krásné kyčelnice devitilisté. Je to bylina z čeledi brukvovitých nápadná pouze bēhem krátké doby, kdy kvete. Strž, v niż roste, jakoby byla do Stredohorii pienesena z horských pralesû. V prameništi rostou stovky kyčelnic, niže jsou okoli drobného potưčku a prilehlé svahy hustè porostlé vyššimi kapradinami nebo devětsilem bilým, nad tím rostou obrovské javory, buky, lipy a dalši.

GPS: $50^{\circ} 38^{\prime} 04,5^{\prime \prime} \mathrm{N}, 14^{\circ} 02^{\prime} 13,3^{\prime \prime} \mathrm{E}$, stanovištè: lesni prameniště ve strmém svahu, kvete: IV, náročnost: velmi vysoká

Figura 1

Extrato de ficha descritiva de uma das biocaches incluídas no guia botânico do vale do rio Labe (República Checa).

Fonte: Botanickýprůvodceficha (2012:16). http://www.usti-nl.cz/images/turistum/tiskoviny/2012_botanicky_pruvodce.pdf 


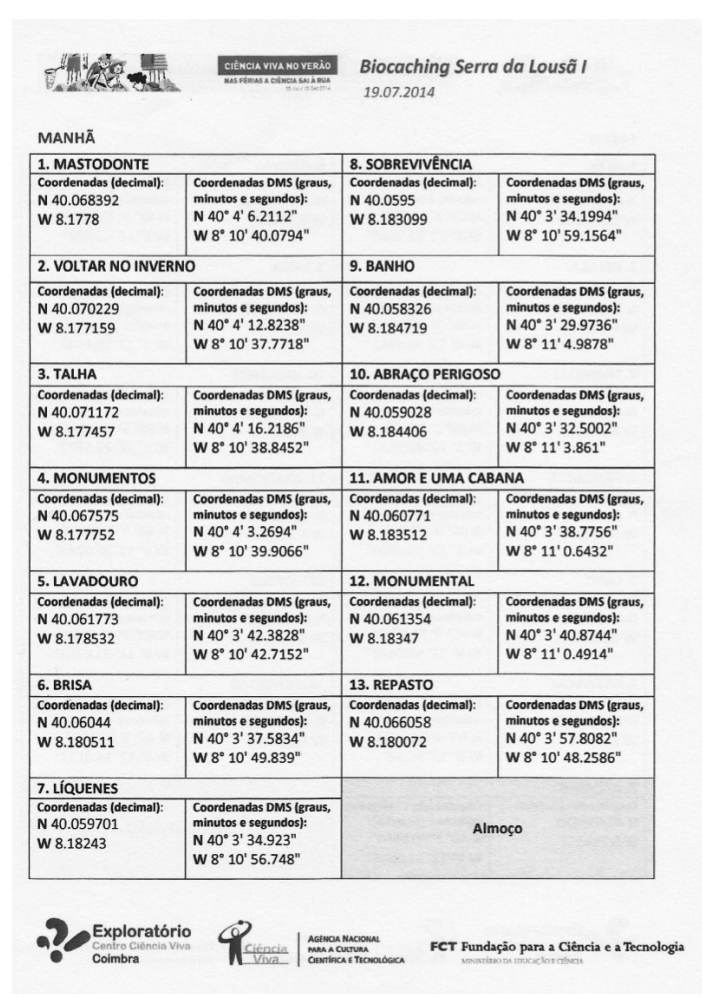

Figura 2

Panfleto com localização das biocaches da atividade "Biocaching Serra da Lousã I”, referente ao período da manhã, do Programa Ciência Viva no Verão (2014)

Fonte: ANCTF (2014)

O caso concreto do biocaching constitui uma aplicação recente como ferramenta de aprendizagem no âmbito da biologia, o que faz desta atividade um domínio de enorme potencial nas estratégias de proteção e valorização do património natural biótico em particular, e dos recursos ecológicos e culturais, em geral, como foi possível constatar através de diversos exemplos mencionados nesta reflexão, e de tantos outros também relevantes, atravessando a escala internacional e nacional.

No seguimento desta reflexão, pensamos apresentar em breve uma proposta de criação de uma rede de biocaching na Serra da Lousã alicerçada nas suas árvores notáveis (de interesse público) e articulada/integrada com outros recursos e/ou produtos já existentes designadamente a Rede Natura 2000 e a Rede das Aldeias do Xisto (na amplitude materializada em lugares, praias fluviais, percursos pedestres e cicláveis), capaz de induzir novos fluxos de visitantes (em particular os que pretendem viver experiências de grande valor simbólico e privilegiam cenários de extrema beleza cénica, traços biofísicos excepcionais, biodiversidade e geodiversidade) e contribuir para a valorização das suas paisagens culturais.

Esta proposta inclui a criação de uma base de dados com as espécies arbóreas já classificadas pelo
Instituto da Conservação da Natureza e das Florestas e catalogadas no Registo Nacional do Arvoredo de Interesse Público, bem como uma série de outras árvores que, segundo os critérios utilizados pela mesma entidade, possam vir a ser classificadas na Serra da Lousã, através de proposta formulada $a$ posteriori, e propostas pelos autores neste artigo.

A valorização de alguns dos exemplares, além da proteção especial adquirida no âmbito da classificação, incluirá uma dinamização com a colocação de geocaches nas árvores seleccionadas, ou na proximidade destas, segundo os critérios estabelecidos pelo Instituto da Conservação da Natureza e das Florestas, em conjugação com a sua integração ou proximidade a lugares, praias fluviais, percursos pedestres e cicláveis, beleza singular dos locais, condições de acessibilidade, com o devido registo no portal geocaching.com.

\section{Referências bibliográficas}

AGÊNCIA NACIONAL PARA A CULTURA CIENTífICA E TECNOLÓGICA (2014). - Ciência Viva no Verão. Nas férias a ciência sai às ruas. Brochura. Lisboa.

ALVES, L. e CARVALHO, P. (2015) - Geocaching e descobertal valorização de territórios rurais. A sua geografia em Portugal e o exemplo da Serra da Lousã. In Carvalho, P. (org.): Lazeres Ativos I. Eumed, Universidade de Málaga, pp. 31-47.

Botanick ýprůvodceficha (2012). Disponível em: http:// www.usti-nl.cz/images/turistum/tiskoviny/2012 botanicky_pruvodce.pdf

CARVALHO, P. (2015) - Lazeres Ativos I. Eumed, Universidade de Málaga.

CURATO, M. (2013) - Uma introdução ao Geocaching. Disponível em: http://www.geocaching.com/tools/ intro.aspx. Acesso a 10/07/2015.

FERNANDES, J. (2013) - "Tecnologia, georreferenciação e novas territorialidades. O caso do geocaching". Cadernos de Geografia, n $30 / 31$ (2011/2012), pp. $171-180$.

JAMAL, T. e ROBINSON, M. (Eds.) (2009) - The SAGE Handbook of Tourism Studies. London, SAGE Publications.

MENEZES, M. R. Calheiros e (2009) - Turismo no Minho: Uma Abordagem de Rede. Dissertação de Mestrado em Engenharia e Gestão Industrial, Universidade de Aveiro.

NETTO, A. P. e GAETA, C. (Orgs.) (2010) - Turismo de Experiência. São Paulo, Editora SENAC.

RICHARDS, G. (2011) - Creativity and Tourism: the State of the Art. Annals of Tourism Research, 38(4), 1225-1253.

PIKE, A.; RODRÍGUEZ-POSE, A. e TOMANEY, J. (Eds.) (2011). Handbook of Local and Regional Development.London and New York, Routledge. 
PUENTE FERNANDEZ, L. (2011) - “El valor patrimonial del paisaje: cultura, medioambiente y democracia". Proceedings of 6th International Congress for Spatial Planning, Madrid, FUNDICOT, 211-225.

SIJMEN T. e JORIS V. (2010) - Duurzame jongeren communicatie met digitale media. Een inventarisatie van good practices eneen pilot study in de praktijk van natuuren duurzaam heidseducatie. SME Advies. Holanda.
SMITH, L. (2006) - Uses of Heritage. London and New York, Routledge.

TIMOTHY, D. e NYAUPANE, G. (Eds.) (2009) - Cultural Heritage and Tourism in the Developing World.A Regional Perspetive. London and New York, Routledge.

THOMAS, E. (2006) - Tips and techniques for creative teaching. IdeaBank, pp. 54-56. Estados Unidos da América. 